\title{
EXPERIMENTAL ANALYSIS OF HEAT TRANSFER AND FluId FlOW IN MICRO-CHANNEL HEAT SINK
}

\author{
Rajesh Sharma, Amoljit Singh Gill and Vikas Dhawan \\ Mechanical Engineering Department, Cec, Landran
}

\begin{abstract}
In this paper heat transfer in single phase through micro-channels was studied. The validation of classical correlations of conventional channels to micro-channels is explored. It is found that classical approach is in good agreement with the experimental results of heat transfer in micro-channels.The material used for micro-channel heat sink (MCHS) is copper, experiments were conducted using water as cooling agent in this study. Micro-channels are made with the help of EDM machine on the upper surface of MCHS. Variation of heat transfer rates, effect of friction factor, effect of pressure drop and variation in temperature distribution is investigated in this study. It is observed in the study that with decrease in velocity flow friction also decreases.
\end{abstract}

\section{KEYWORDS}

micro-channel; electronics cooling; friction factor

\section{INTRODUCTION}

Micro-channel heat exchangers are extensively used in various applications and industries for saving energy and resources. Investigation of micro-channels is based on the single phase internal flow correlation for convective heat transfer:

$$
h=N_{u} \frac{k}{D_{h}}
$$

Nusselt number remains a constant for internal flow. Above mentioned correlation is investigated by Tuckerman and pease [1]. Their results encouraged and motivated others to investigate heat transfer in micro-channels. Due to miniaturizations of the electronic components and due to space considerations and demand for high speeds, the cooling of electronic components has become a tough challenge. So we need compact heat exchangers which can cool these components at faster rates and may be small in their size so, micro channel type compact heat exchangers offer advantages due to higher heat transfer coefficients. The large surface to volume ratios helps in enhanced heat transfer rates in micro-channels.

Micro-channels are the heat sinks which can transfer large amount of heat and can be fabricated by different techniques [2]. Micro-channels were used first time by Tuckerman and Pease [1] .They used water as a coolant under laminar conditions through micro-channels. They used micro-channels for electronics cooling and able to achieve heat fluxes as high as $790 \mathrm{~W} / \mathrm{cm}^{2}$ with the chip temperature maintained below $110^{\circ} \mathrm{C}$. Various other authors investigated heat transfer in micro-channels [3-7].

X.F. Peng et al. [8] concluded that for flow in micro-channels, the low values of the inner diameter limit the significance of the mixed convection. Chein-Yuh Yang et. al.[9] investigated that at lower values of Re (Reynolds No.) the temperature variation increases along length and DOI: 10.14810/ijmech.2016.5302 
heat losses are higher in the downstream. As the value of Re increases thermal resistance and friction factor decreases but pressure drop, heat transfer coefficient and pumping power increases [10].

Surface roughness plays an important role in the micro-channel performances [11], since at micro level it is nearly impossible to obtain smooth surface. Large roughness of the micro-channel causes high friction factor [12-13]. The convective heat transfer rate can be enhanced by varying boundary conditions, geometry, or by enhancement of thermal conductivity of the fluid [14]. Nowadays nano particles are used for the enhancement of heat transfer rates but they also rises presuree drop [15-19].

The controlling factors for the enhanced heat transfer in micro-channels are velocity of working fluid ,type of heat transfer i.e. single phase or vapor phase, type of material used for heat exchanger , pressure drop and friction factor.

In present study investigations are made on the above mentioned factors and presented in the form of figures or graphs. It is observed that the conventional heat transfer relations and equations are also applicable to microchannels. Various literatures [1,20-23] also validate the same.

\section{EXPERIMENTAL SETUP AND Procedures}

Water as a working or cooling fluid is taken from a reservoir with the help of a pump, which provides steady and smooth flow over wide range of flow rates. Flow rate from $0.3 \mathrm{~L} / \mathrm{min}$. to 3.5 $\mathrm{L} / \mathrm{min}$ are used in this investigation. The fluid enters into the copper micro-channel test section through inlet plenum. The fluid takes the heat from the micro-channel test section, which is heated by using cartilage heating system. Hot fluid then exits from the test section and passes through the heat exchanger which is used for lowering the temperature of working fluid i.e. water. After that working fluid goes to reservoir. Closed loop cooling system is used in the experimental set-up.

The equivalent hydraulic diameter was calculated using the following expression:

$$
D_{h}=4 A / P
$$

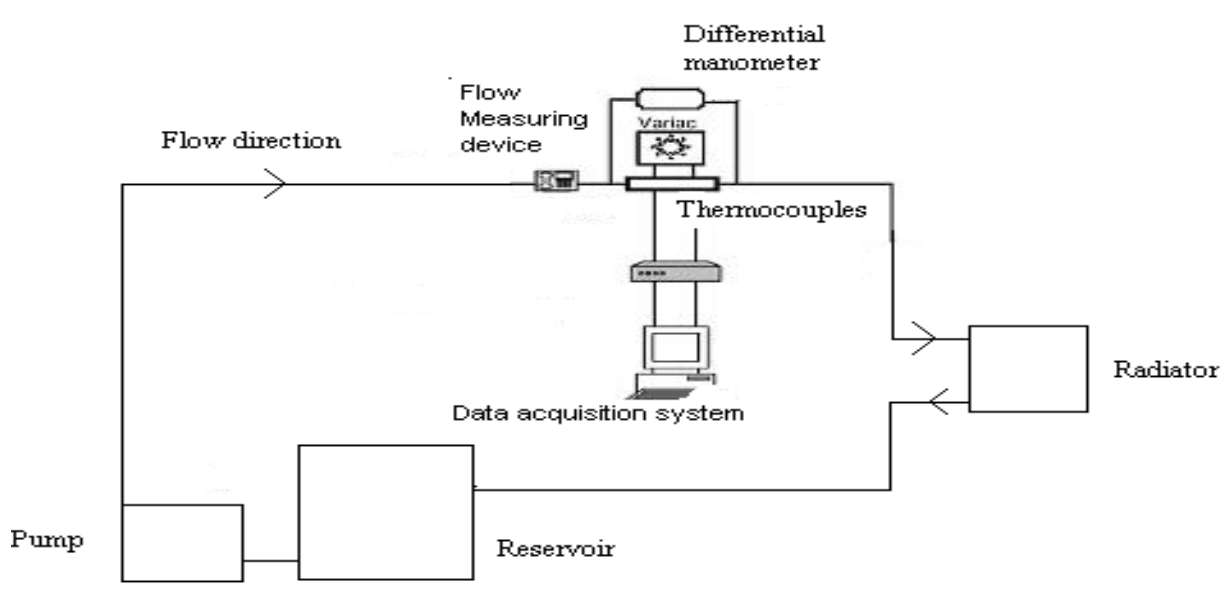

Figure 1 Flow Diagram Experimental Setup 
Thermocouples were used to measure the temperatures of micro-channel walls (shown in Figure 2). Data acquisition system as shown in Figure 3 is used to read the temperatures and provides temperature distribution across the length of micro-channels. Heat gain by the coolant is provided by the following equation:

$$
q=\rho c_{p} Q\left(T_{m, o}-T_{m, i}\right)
$$

where $\mathrm{Q}$ is volumetric flow rate, $\left(T_{m, o}\right.$ and $\left.T_{m, i}\right)$ inlet and outlet fluid temperatures.

The actual picture of micro-channel heat sink is shown in Figure 4.The heat transfer coefficient is determined from the following relation:

$$
h=q /\left[N A\left(T_{w}-T_{m}\right)\right]
$$

The desired flow rates are obtained with the help of needle valve used in the circuit. After the stabilization of flow, heat is supplied to the MCHS through cartridge heaters provided in the bottom of MCHS. The temperature measurements from all the sensors were stored using data acquisition system during the experimentations. Following correlations given in Table1 are used for investigations.

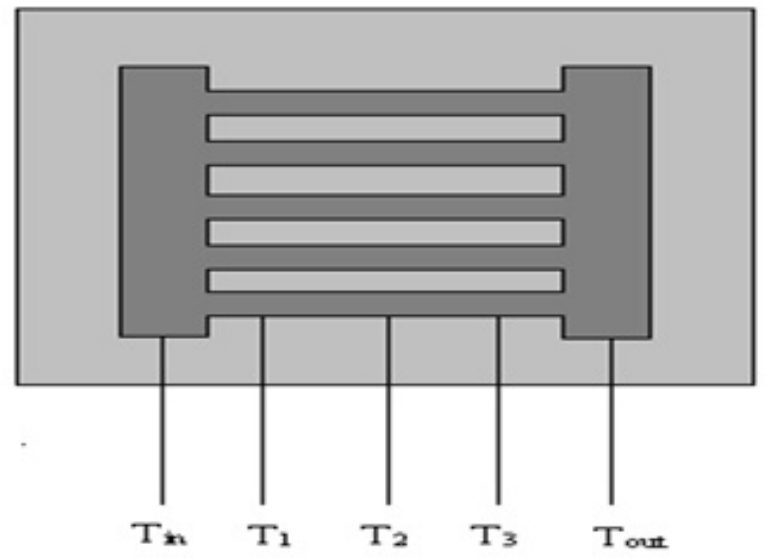

Figure 2 Position of Thermocouples in Micro Channel

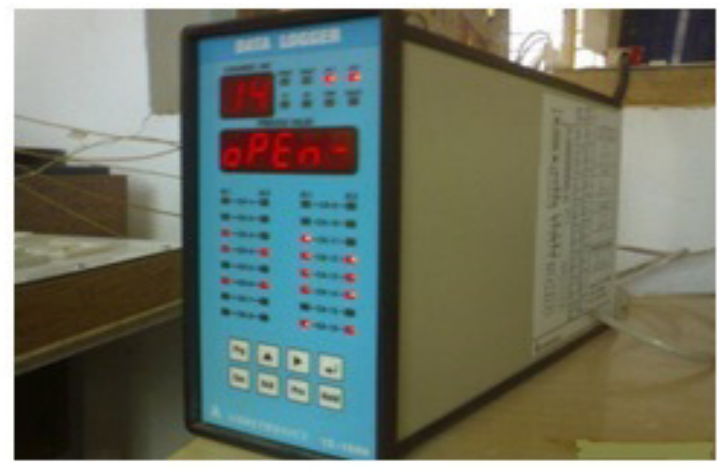

Figure 3 Data Acquisition System Heat Sink 


\section{RESUlts AND DISCUSSION}

The heat transfer correlations used for laminar flows in channels are shown in Table 1 these correlations have been widely used in the literature for comparison against experimental results for micro-channels. The correlations presented in the table are according to different flow and boundary conditions.

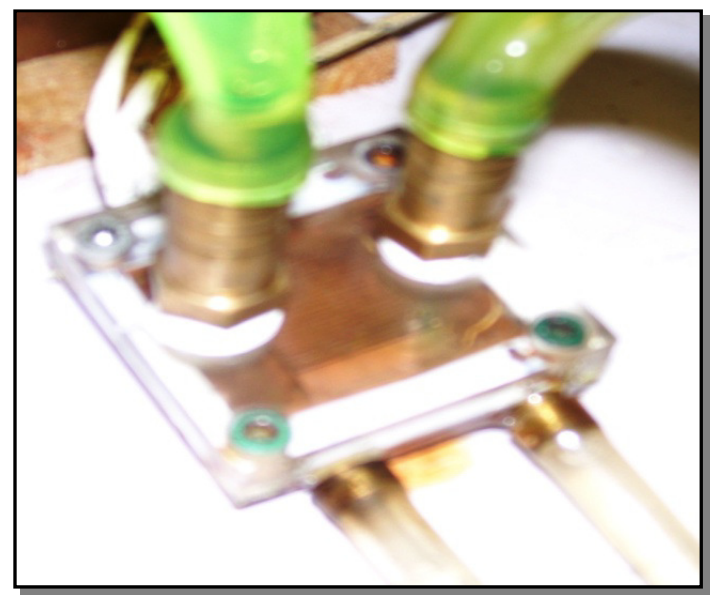

Figure 4 Actual Microchannel Heat Sink with Adapters

Table 1 Convection Correlations for Flow in a Micro Channel Heat Sink

\begin{tabular}{|l|l|}
\hline conditions & Correlations \\
\hline Laminar fully developed & $\frac{64}{\mathrm{Re}}$ \\
\hline $\begin{array}{l}\text { Laminar fully developed, uniform } \\
\text { heat flux } \\
\operatorname{Pr} \geq 0.6\end{array}$ & $\mathrm{Nu}=4.36$ \\
\hline $\begin{array}{l}\text { Laminar fully developed, uniform } \\
\mathrm{T}_{\mathrm{s}}, \\
\operatorname{Pr} \geq 0.6\end{array}$ & $\mathrm{Nu}=3.66$ \\
\hline $\begin{array}{l}\text { Laminar, thermal entry length, } \\
\text { uniform Ts }\end{array}$ & $\overline{\mathrm{Nu}}=3.66+\frac{0.0668(D / L) \operatorname{Re} \operatorname{Pr}}{1+0.04[(D / L) \operatorname{Re} \operatorname{Pr}]^{2 / 3}}$ \\
\hline
\end{tabular}

The changes in pressure drop with respect to velocity i.e. Reynolds no. is shown in Figure 5. It was observed that with increase in velocity the pressure drop also increases.But it is also observed that effect of heat flux on pressure drop is negligible. 
International Journal of Recent advances in Mechanical Engineering (IJMECH) Vol.5, No.3, August 2016

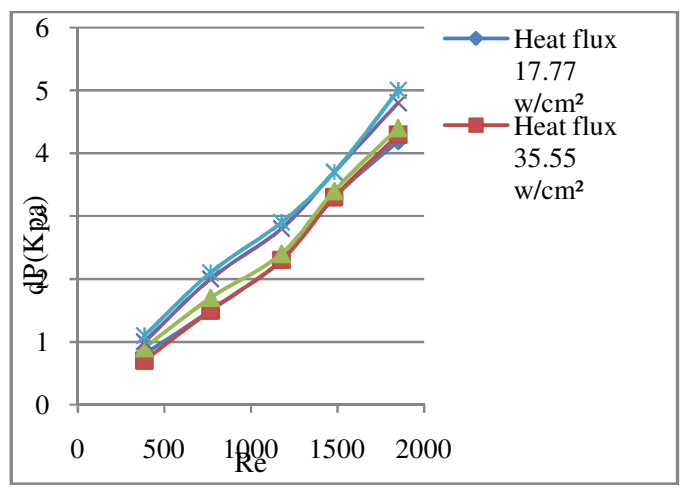

Figure 5 Reynolds Number Versus Pressure Drop at Different Heat Fluxes

The variation of experimental fanning friction factor with Reynolds number varying from 350 to 2200 is shown in Figure 6 for micro-channels having hydraulic diameter $0.61 \mathrm{~mm}$ and depth 2.5 $\mathrm{mm}$. It was observed that fanning friction decreases up to certain limit with increases in Reynolds no. and after that it decreases. The shape of the graph was observed as ' $\mathrm{S}$ ' in shape.

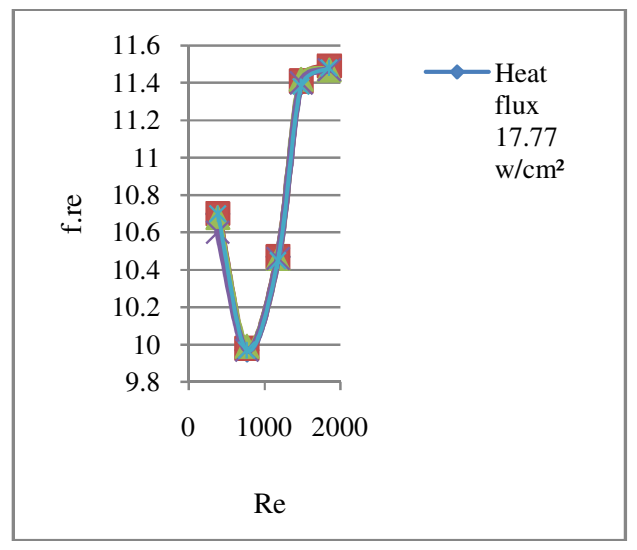

Figure 6 Reynolds Number Versus Fanning Friction Factor .

It has been from the Figure 7 that there is negligible effect of heat flux on fanning friction. As seen form figure that the fanning friction line remains straight with variation in heat flux values. 
International Journal of Recent advances in Mechanical Engineering (IJMECH) Vol.5, No.3, August 2016

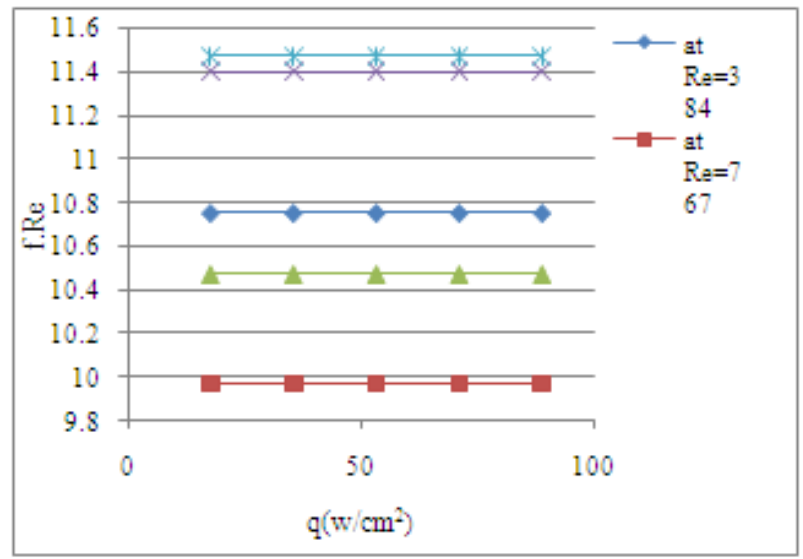

Figure 7 Heat Flux Verses Fanning Friction at Different Reynolds Numbers

It was observed that with increase in mass flow rate, the heat transfer rate also increases, which is given by the relation

$$
q^{\prime \prime}=m c_{p} \Delta T
$$

So with large mass flow rates rise in temperature of micro-channel walls becomes low i.e. cooling will be better.

Same trends were observed for other heat fluxes, as shown in Figures 8 (a),(b), (c) and (d).As flow rate was increased from 0.5 LPM to $2.5 \mathrm{LPM}$, it was observed that the heat removal rate also increases rapidly.It is also seen from the figure that with increases in flow rate of microchannels will be able to resist the increase in temperature.

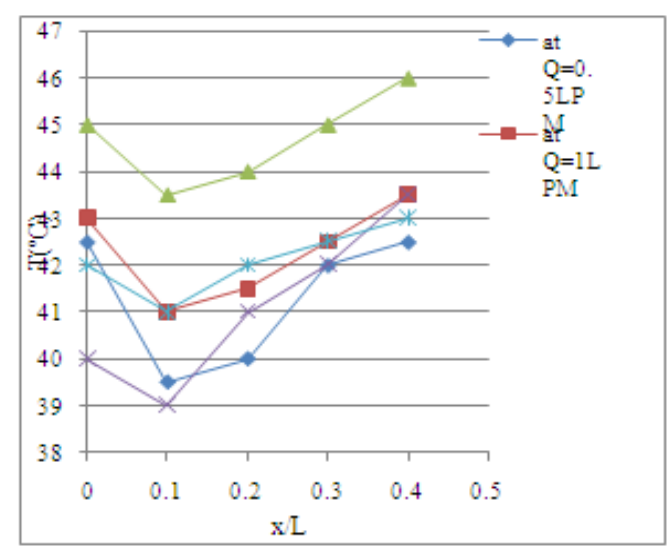

(a)

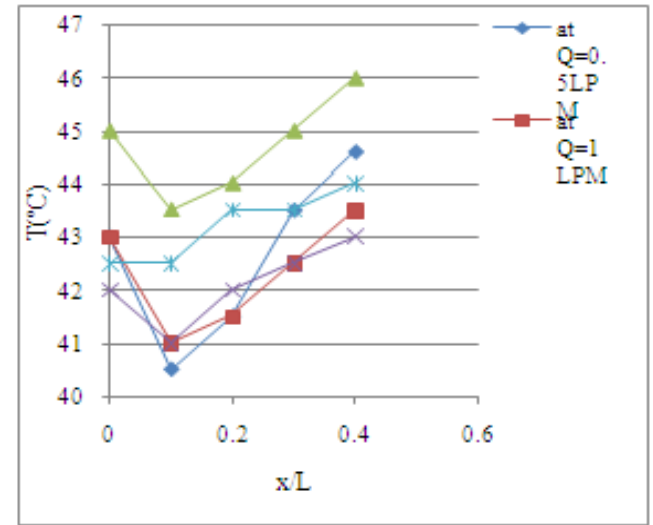

(b) 


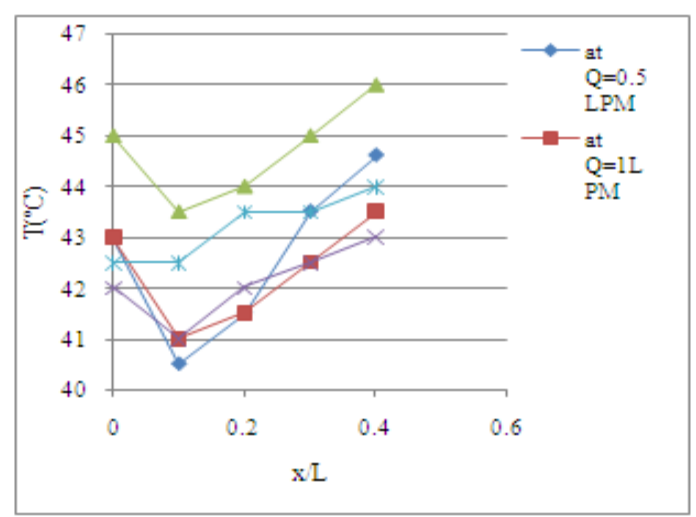

(c)

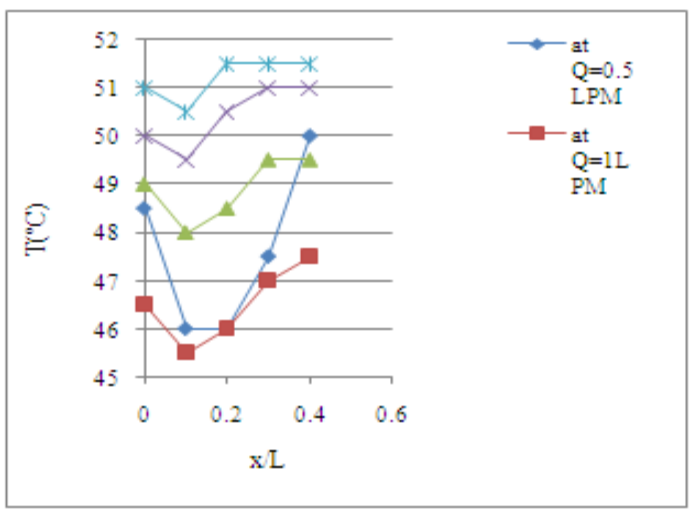

(d)

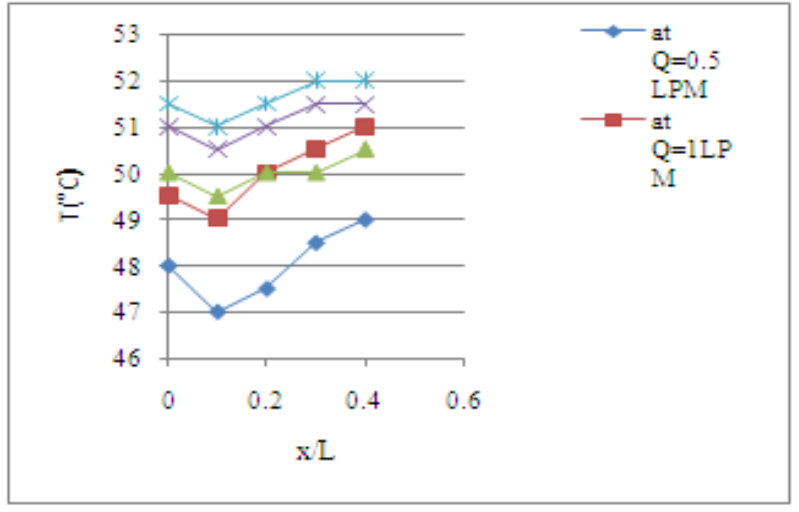

(e)

Figure 8 Temperature distributions along the length of micro channel heat sink (MCHS) in nondimensional form at different flow rates (a) $17.77 \mathrm{~W} / \mathrm{cm}^{2}$, (b) $35.55 \mathrm{~W} / \mathrm{cm}^{2}$, (c) $53.33 \mathrm{~W} / \mathrm{cm}^{2}$, (d) 71.11 $\mathrm{W} / \mathrm{cm}^{2}$ and (e) $88.88 \mathrm{~W} / \mathrm{cm}^{2}$

\section{Conclusion}

Experimental analysis was made for the fluid flow and heat transfer with micro-channels. The conclusions made throughout the study are discussed in this section. When mass flow rate decreases, friction factor also decreases due to decrease in velocity of flowing fluid. The pressure drop increases with increase in velocity of fluid, thereby increases heat flux removal rate. Initially fanning friction factor decreases as there is increase in mass flow rate. But after certain value of mass flow rate it starts increasing. The heat transfer rate from MCHS increases with increase in mass flow rate. And in turn pressure loss is converted into heat which is carried by the water which was used as cooling agent.So it is observed that conventional mathematical correlations or equations used for conventional channels can be used for micro-channels. 


\section{REFERENCES}

[1] D.B. Tuckerman, R.F.W. Pease, High-performance heat sinking for VLSI, IEEE Electron Dev. Lett. 2 (1981) 126- 129.

[2] Monica Nadasan and Adrian Manea Design and fabrication of the microchannels For micro-fluidics applications U.P.B. Sci. Bull., Series C, Vol. 71, Iss. 4, 2009

[3] Chungpyo Hong, Yutaka Asako, Heat Transfer Characteristics of Gaseous Flows in Microtube With Constant Heat Flux, Applied Thermal Engineering 28 (2008) 1375-1385.

[4] Daniel Haller, Peter Woias, Norbert Kockmann: Simulation and Experimental Investigation of Pressure Loss and Heat Transfer in Microchannel Networks Containing Bends and T-Junctions International Journal of Heat and Mass Transfer 52 (2009) 2678-2689.

[5] G. Gamrat 1, M. Favre-Marinet, S. Le Person: Modelling of Roughness Effects on Heat Transfer in Thermally Fully-Developed Laminar Flows Through Micro-channels, International Journal of Thermal Sciences 48 (2009) 2203-2214.

[6] G. Hetsroni, A. Mosyak, Fluid Flow in Micro-Channels, International Journal of Heat and mass transfer 48 (2005)

[7] B. Xu, K.T. Ooi, N.T. Wong, W.K. Choi, Experimental investigation of flow friction for liquid flow in microchannels,Int. Comm. Heat Mass Transfer 27 (2000) 1165-1176.

[8] X.F. Peng, G.P. Peterson, Convective heat transfer and flow friction for water flow in micro-channel structures, Int. J. Heat Mass Transfer 39 (1996) 2599-2608.

[9] Chein-Yuh Yang, Chia-Wei Chen, Ting-Yu Lin, Satish Kandlikar. Heat Transfer and Friction Characteristics of Air Flow in Microtubes, Experimental Thermal and Flud Science 37 (2012) 12-18.

[10] B. S. Gawali S. D. Thakre V. B. Swami Theoretical and Experimental Investigation of Heat Transfer Characteristics through a Rectangular Microchannel Heat Sink International Journal of Innovative Research in Science, Engineering and Technology Vol. 3, Issue 8, August 2014.

[11] Giulio Croce , Paola D'agaro, Carlo Nonino: Three-Dimensional Roughness Effect On Micro-channel Heat Transfer And Pressure Drop, International Journal of Heat and Mass Transfer 50 (2007) 5249-5259.

[12] Mesbah G. Khan and Amir Fartaj, A Review on Microchannel Heat Exchangers and Potential Applications, International Journal of Energy Research; 35:553-582 (2011).

[13] Zeng-Yuan Guo, Zhi-Xin Li, Size Effect on Microscale Single-Phase Flow and Heat Transfer, International Journal of Heat and Mass Transfer 46 (2003) 149-159.

[14] Zhuo Li, Ya-Ling He, Gui-Hua Tang, Wen-Quan Tao, Experimental and Numerical Studies of Liquid Flow and Heat Transfer in Microtubes, International Journal of Heat and Mass Transfer 50 (2007) 3447-3460.

[15] Mushtaq I. Hasan. Numerical Investigation of Counter Flow Micro-channel Heat Exchanger with MEPCM Suspension. Applied Thermal Engineering Volume 31, Issues 6-7, May 2011, Pages 1068-1075.

[16] S.M.Peyghambarzadeh, S.H.Hashemabadi, Experimental Study of Heat Transfer Enhancement Using Water/Ethylene Glycol Based Nanofluids as a New Coolent for Car Radiator, International Communication in Heat and Mass Transfer 38 (2011) 1283-1290.

[17] Sarit Kumar das Stephen U.S. Choi, - Heat Transfer in Nanofluids- A Review Journal of Heat transfer engineering 27(2010):3-19.

[18] Tu-Chieh Hung,Wei-Mon Yan, Xiao-Dong Wang, Chun-Yen Chang Heat transfer enhancement in microchannel heat sinks using nanofluids International Journal of Heat and Mass Transfer (2012) .

[19] Yi-Hsuan Hung, Tun-Ping, Tun-Chien Teng,Assessment of Heat Dissipation Performance for Nanofluid, Applied Thermal Engineering 32(2012) 132-140.

[20] G.M. Mala, D. Li, J.D. Dale, Heat transfer and fluid flow in micro-channels, Int. J. Heat Mass Transfer 40 (1997) 3079-3088.

[21] X.F. Peng, G.P. Peterson, B.X. Wang, Heat transfer characteristics of water flowing through microchannels,Exp. Heat Transfer 7 (1994) 265-283.

[22] A.Popescu, J.R. Welty, D. Pfund, D. Rector, Thermal measurements in rectangular micro-channels, in: Proceedings of IMECE2002, IMECE2002-32442, 2002.

[23] Satish G. Kandlikar and Harshal R. Upadhye, Extending the heat flux limit with enhanced microchannels in direct single phase cooling of computer chips", Proc. 21st IEEE semi-therm symposium, 2005. 